\title{
The effect of performance-oriented funding in higher education: evidence from the staff recruitment budget in Italian higher education
}

\author{
Nicoletta Fadda ${ }^{1}$ (D) $\cdot$ Ludovico Marinò $^{1} \cdot$ Gianfranco Pischedda $^{1} \cdot$ Alberto Ezza $^{1}$
}

Accepted: 19 May 2021/ Published online: 27 May 2021

(C) The Author(s) 2021

\begin{abstract}
This study, which aims to investigate some potential effects derived from the adoption of performance-oriented funding in the higher education system, is focused on competitive allocative mechanism to provide universities with the staff recruitment budget in the Italian Higher Education System using panel data spanning the period 2012-2018 for 58 public universities. Results show that the geographical area in which universities operate influences their capacity to increase performance and thus financial resources. Indeed, universities located in Northern areas, the wealthier part of Italy, received a higher amount of resources than those located in the rest of the country. These findings reveal the key role played by external factors, which are beyond the control of management, in universities' capacity to achieve better performance. Results also suggest that policymakers should identify the correct trade-off between the quest for higher performance within the Italian Higher Education System and equity in resource allocation.
\end{abstract}

Keywords Resource allocation · Performance-oriented funding · Italian Higher Education System · Recruitment · 'Punti-organico' · Equity in funding

\section{Introduction}

The rationale behind the adoption of performance in higher education (HE) financing is to reward the best-performing institutions to stimulate higher competitiveness, hence forcing the worseperforming institutions to change their strategy in order to raise their performance (Hicks, 2012). Considering the vital role played by human resources in $\mathrm{HE}$ in providing a competitive edge and sustainable results for universities (van den Brink et al., 2013), the adoption of a competitive approach in resource allocation can potentially have an overwhelming effect on universities'

Nicoletta Fadda

nfadda@uniss.it

1 Department of Economics and Business, University of Sassari, Via Muroni n. 25, 07100 Sassari, Italy 
strategic behaviour. However, the adoption of performance measures in HE funding allocation can lead to unintended consequences (Umbricht et al., 2017), such as opportunistic behaviours, gaming practices, or the so-called Matthew effect. These can widen the gap between universities (Jeon \& Kim, 2018; Merton, 1968) and may produce or perpetuate inequalities linked to historical trends or contextual factors beyond the control of universities' management.

This article focuses on the particular mechanism used by the Italian government to provide universities with the annual budget for staff recruitment ${ }^{1}$ (academic and administrative staff). Although a large body of literature has been produced on performance-oriented funding, further studies are required to examine the potential effects of these mechanisms in specific state contexts (Dougherty et al., 2016). To contribute to the debate on this topic, this work aims to understand if the mechanism introduced to allocate the recruitment budget has led to an allocation of resources that could undermine equity between universities in terms of government funding. Using data provided by the Ministry of Education, a multivariate quantitative analysis was carried out, aimed at understanding if the geographical location of a university exerts an impact on the resources available for recruitment policies.

\section{Literature review}

\section{Performance-oriented funding in HE}

The models for financing public universities can vary between systems. Differences can be found in terms of activities funded, performance indicators used, etc. For this reason, governments can develop differentiated models. According to the existing literature (Johnstone et al., 1998), budgeting systems can be divided into two main groups: traditional budgeting methods (such as formula financing) that are often based on historical data about the number of students, number of staff or staff salaries (Salmi \& Hauptman, 2006) and modern budgeting methods (such as performance-based budgeting, performance-based funding, etc.) which link funding levels to some measure of output or outcome that is predetermined by the Ministry.

Despite the differences, these competitive schemes share a common underlying assumption: rewarding better-performing universities with a higher level of funding will stimulate worse-performing institutions to change their strategic behaviour to meet performance requirements (Herbst, 2007). Following these approaches, each university, particularly those with limited financial resources, should react to government regulations to increase performance and secure higher levels of funding (Hagood, 2019).

In light of the broad adoption of performance in HE funding allocation, several studies have examined the effectiveness of performance-based resource allocation (Liefner, 2003). However, the actual impact of competitive funding elements on universities' behaviour cannot be easily forecast, since universities' reactions follow a non-linear and non-deterministic pattern (Nisar, 2015), and institutions can focus on a restricted area of objectives while reducing overall performance. Starting from these assumptions, one potential issue in the use of performance-oriented mechanisms in HE resource allocation is related to emergence of unintended consequences (Geuna \& Martin, 2003; Umbricht et al., 2017), identified as 'outcomes that are not intended by the enacting body, but which arise as side effects of

\footnotetext{
${ }^{1}$ In this work, 'recruitment' and 'recruitment policies' are used with a broader meaning, to include both the recruitment of new academics and administrative staff and their career advancement.
} 
funding institutions based on their performance' (Dougherty \& Reddy, 2013, p. 13). Furthermore, if performance strongly varies within a system, the adoption of performance-oriented mechanisms could produce uneven competition, especially if universities work in underprivileged areas and are historically characterized by heterogeneous performance. Indeed, competitive mechanisms will 'perpetuate inequities in funding that existed before the advent of the formula' (McKeown, 1996, p. 9). In this case, the funding mechanism is not able to guarantee vertical equity between institutions, which 'recognises that not all institutions or groups of students they serve are equal' (Li et al., 2018, p. 293), because of social and economic injustices. In the funding equity framework (Dowd \& Grant, 2006; Li et al., 2018; Musgrave, 1959), vertical equity is complementary to horizontal equity, which deals with equal treatment of equals. In this case, resource allocation can be based on a formula that takes into consideration factors such as enrolment size, while methods of reducing inequities and ensuring vertical equity should be based on the allocation of special funds.

The adoption of performance-oriented funding in environments that are characterized by pivotal differences could affect the institutions' capacity to achieve performance and can subsequently stimulate a 'Matthew effect', by strongly restricting the access to funds of worseperforming institutions and supporting the best-performing institutions (Jeon \& Kim, 2018; Merton, 1968). In this way, 'rich' universities will become richer and 'poor' universities will become poorer, and HE will gradually become a 'winner-takes-all' market (Frank \& Cook, 2010).

Consequently, this type of budgeting system (especially if formula-based) is likely to undermine the universities that operate under negative conditions, e.g. serving disadvantaged areas characterized by high levels of unemployment, weak social and transport networks, poor labour opportunities, etc. In such environments, performance diversity can be at least partially explained by external factors, e.g. differences in wealth, employment rate, etc., and a performance-funding allocation will perpetuate and widen inequalities.

Thus, governmental funding to universities should support those institutions that serve underprivileged populations, thereby guaranteeing vertical equity by assuring an adequate level of resources ( $\mathrm{Li}$ et al., 2018). In fact, $\mathrm{HE}$ is a merit good, and universities generate positive externalities that benefit the surroundings (Dotti et al., 2013). The reduction of public subsidies could threaten the survival of those institutions located in rural and disadvantaged areas and amplify 'brain drain' towards wealthier areas (Ciriaci, 2014). The importance of universities to local development arises from a number of different main factors, such as knowledge creation and transfer (Faggian \& McCann, 2008), the upgrading of the social and political system and the impacts on the industrial environment (Dotti et al., 2013).

Starting from the adoption of performance in financing HE, the work in the present article aims to understand whether the use of performance indicators in the allocation of staff recruitment budgets can generate unintended consequences. After analysing the mechanism to allocate the recruitment budget for universities introduced in the Italian Higher Education System (IHES), the work tries to explain if this performance mechanism affects equity with respect to serving institutions located in disadvantaged areas. To achieve this purpose, the study anchors its perspective on vertical and horizontal equity. Table 1 shows the main theories, research streams and studies that form the basis of the theoretical framework.

\section{Funding in the IHES}

Despite the international trends that saw the growing relevance of private universities, the IHES can still be largely considered public. Indeed, similarly to other European countries, e.g. 
Table 1 Main theories and research streams of the theoretical framework

\begin{tabular}{ll}
\hline Theories and research streams & Studies \\
\hline Performance-oriented funding & Johnstone et al., 1998 \\
& Jongbloed, 2004 \\
& Salmi \& Hauptman, 2006 \\
Unintended consequences of performance-oriented funding & Jongbloed et al., 2017 \\
& McKeown, 1996 \\
& Geuna \& Martin, 2003 \\
Equity in resource allocations in (HE) institutions & Jongbloed, 2004 \\
& Dougherty \& Reddy, 2013 \\
& Dougherty et al., 2016 \\
& Umbricht et al., 2017 \\
& Musgrave, 1959 \\
& Berne \& Stiefel, 1984 \\
& Dowd \& Grant, 2006 \\
\hline
\end{tabular}

Germany, Austria, France and Spain, state universities play a fundamental role in Italy, since $89 \%$ of students are enrolled in a public-owned institution. Furthermore, the role of government is still relevant since it plays a pivotal role in steering HE policies, e.g. degree requirements, course accreditation, etc., that influence both state and private universities. Italian state universities went through a complex and enduring process of reforms aimed at fostering their performance and the sustainability of public finance. The reform process also involved the private universities, since they share the same set of rules as the state universities in numerous aspects, especially regarding teaching activity, e.g. classification of degree courses, mandatory characteristics of curricula, self-evaluation, initial accreditation and subsequent re-accreditation of degree courses.

Given that the survival and development of state universities are strictly linked to access to public subsidies, the government has imposed a strong incentive to change universities' strategies, behaviours and internal processes (Liefner, 2003). Competition, performance measurement and assessment have, over time, had a pivotal role in the IHES (Andresani \& Ferlie, 2006). In line with the idea that resources should flow to institutions where performance is manifested (Jongbloed et al., 2017), the Italian government has implemented several performance-oriented mechanisms. Universities' core budgets (the 'Fondo di Finanziamento Ordinario' - FFO) are allocated using a quasi-market approach (Ezza et al., 2017) in combination with a formula-based mechanism that is mainly focused on research outcomes. Along with these mechanisms, recent legislation introduced a performance-driven system by which funds are allocated specifically for staff recruitment.

The allocation of budgets for academic and administrative staff recruitment is a separate funding mechanism that accounts for more than $€ 2.2$ billion for 2019 (see Ministerial Decree 740/2019). The distinctive feature of the current allocative mechanism is the introduction of a metric - the so-called Punto Organico (PO) - which is equivalent to the average cost of a full professor. In 2018, one PO equalled $€ 113,774$ and was used to parametrize the average cost of all the other academic or administrative positions, i.e. one associate professor equals 0.7 PO; one fixed-term research fellow varies from 0.4 to $0.5 \mathrm{PO}$; one executive equals $0.65 \mathrm{PO}$, etc. POs inform all the regulations regarding university recruitment, since all financial provisions are converted using this measure. The theoretical model implies that the total number of POs (the entire budget available for state universities' recruitment policies) 
allocated to Italian universities is defined with reference to the number and type of employees (both academic and administrative staff) who left each university the previous year. In other words, a parameter ('Turnover POs') is calculated with reference to each institution to weight staff reduction, and the recruitment budget is defined as the sum of the Turnover POs for each institution.

However, the actual number of POs allocated at national level from 2012 to 2017 did not equal the theoretical values obtained as previously described. In fact, the definition of this metric dealt with the so-called turnover block, i.e. the limitations in recruitment for public administrations introduced to reduce public spending. Contrary to the other public sectors, the turnover blocks within the IHES were shifted from the single institution to the whole system. In fact, starting from the 2012, the actual number of POs allocated to Italian universities was defined as a share (from $20 \%$ in 2012 to $80 \%$ in 2017) of the theoretical value. Only in the 2018 was the total number of POs equal to the theoretical value.

Finally, the recruitment budget is then shared through a formulaic method that uses the two following efficiency parameters, especially focused on personnel expenses:

A. A staff cost indicator that is calculated as the ratio of personnel expenses to total revenues, i.e. the sum of state funds and tuition fees net of loan repayments;

B. An economic and financial sustainability indicator that is the result of the ratio of total revenues after reducing rents payable to personnel expenses plus amortization charges.

Using these two parameters, the legislation (see Ministerial Decree 740/2019) identifies three groups of institutions:

1. Virtuous institutions: (indicator $\mathrm{A}<80 \%$ or indicator $\mathrm{B}>1$ ), which receive a fixed share or resources (equal to the $50 \%$ of their Turnover POs) increased by an additional rewarding budget. Institutions falling in this group are awarded a higher share of POs than the worst-performing institutions. In other words, universities that meet the governmental goals receive an amount of resources higher than their Turnover POs and can adequately support and renew their staff.

2. Non-virtuous institutions (indicator $\mathrm{A}>80 \%$ or indicator $\mathrm{B}<1$ ), which receive a maximum of $50 \%$ of their Turnover POs;

3. Worst institutions: universities showing a severe financial crisis (indicator A $>80 \%$ ). These institutions do not receive any funds for recruitment policies.

Finally, each university receives a share of POs (Total POs) which is the result of the sum of two components: a 'basic share' (since 2014) that identifies the minimum number of POs allocated to each university and an 'additional share' that rewards the best-performing universities. Both measures are calculated as a percentage of Turnover POs, thus considering the differences in size within the IHES. Table 2 summarises indicators for POs allocation as provided for in the Ministerial Decree 740/2019.

Through the two aforementioned parameters, the Italian legislature identified a way to assess performance, understood as an efficient use of resources with particular reference to human resources (the main university cost item) and indebtedness. This mechanism enables the university to play on the following levers: reducing personnel expenses, writing off rental and loan costs (reducing the inputs), or increasing total revenues (increasing the output). Focusing on revenues, universities can raise tuition fees (higher revenue per student), improve 
Table 2 PO allocation (Ministerial Decree n. 740/2019)

\begin{tabular}{|c|c|c|}
\hline Indicators & $\begin{array}{l}\text { A. Personnel expenses on the total revenues } \\
\text { B. Economic and financial sustainability }\end{array}$ & \\
\hline Performance area & Financial efficiency & \\
\hline & 1. Non-virtuous universities & 2. Virtuous universities \\
\hline Requirements & $\begin{array}{l}\text { (Personnel expenses/Total revenues } \\
\text { (public funding plus students' fees) }>80 \% \\
\text { or }\end{array}$ & $\begin{array}{l}\text { (Personnel expenses/Total revenues } \\
\text { (public funding plus students' fees) } \\
<80 \%\end{array}$ \\
\hline & $\begin{array}{l}\text { (Total revenues after reducing rents } \\
\text { payable/Personnel expenses plus } \\
\text { amortization charges) }<1\end{array}$ & $\begin{array}{l}\text { or } \\
\text { (Total revenues after reducing rents } \\
\text { payable/Personnel expenses plus } \\
\text { amortization charges) }>1\end{array}$ \\
\hline $\begin{array}{l}\text { PO allocated: } \\
\text { basic share }\end{array}$ & $50 \%$ Turnover POs & $50 \%$ Turnover POs \\
\hline $\begin{array}{l}\text { PO allocated: } \\
\text { additional share }\end{array}$ & & $\begin{array}{l}\text { 20\% Margin (Total revenues after } \\
\text { reducing rents payable/Personnel } \\
\text { expenses plus amortization charges) }\end{array}$ \\
\hline
\end{tabular}

enrolments or expand the amount of the state funding received (FFO). With regard to tuition fees, it is important to highlight that universities cannot exceed the threshold of the $20 \%$ of the total amount of the $\mathrm{FFO}^{2}$, the main state funding mechanism by which the central government allots resources to public universities. However, several universities did not comply with this limit.

By adopting input measures (in particular human resources costs) as performance parameters in the formula, the PO mechanism appears to move away from the common evolution highlighted by the literature about performance-based funding mechanisms in HE. Referring to the framework proposed by Jongbloed (2004), PO allocation seems to be a hybrid model, since it clearly shares the underlying objective of a performance-based funding mechanisms but still strongly relies on input metrics instead of output/outcomes.

This paper aims to contribute to the debate about the effects produced by the use of performance metrics to share resources, by focusing on the specific mechanism of resource allocation for the budgets for academic and administrative staff recruitment. It aims to understand if the environmental context, which incorporates all the socioeconomic features of the territories where universities are located, could affect a university's capability to meet the performance goals used in PO allocation. The underlying assumption is that the capability to reach the desired level of performance - efficiency in personnel costs in relation to revenue - is strongly influenced by external factors.

In fact, an important role in the capability to reach the desired level of performance is played by a university's attractiveness. The higher the attractiveness of a university, the higher the revenues in terms of state funding received (FFO), which are proportionate to the numbers of students, and tuition fees. The ability of a university to attract students is only partially manageable by the governance of universities. Rather, it also depends on external factors, such as the reputation of a university, the quality of life of the territory in which the university is located, the work opportunities in a geographic area and the transport system. Therefore, we can consider two different geographical settings where universities are located: an attractive setting and an unattractive setting. The attractive setting is a thriving ecosystem characterized by a blooming economic and social fabric with a high quality of life, major labour

${ }^{2}$ Article 5 Decree President of Republic 25 th July 1997 n. 306. 
opportunities, a good transport system and higher average wealth. In this context, universities are able to attract more students and therefore have a higher incoming student mobility rate and a lower outgoing student mobility rate. Young people from different geographical contexts should be attracted to universities located in this area. These universities act in a privileged position as they have a higher potential to increase outputs to achieve better performance, which in turn have a positive impact on the ability to receive more POs. Moreover, this advantage should trigger a virtuous process in which universities from an already favourable starting point can strengthen their positions. In contrast, the unattractive area is characterized by a poor economic and social fabric, low quality of life, scarce labour opportunities, out-ofdate infrastructure and a lower average wealth. Young people are more likely to leave education early before getting a degree, or they may leave the area for education, but mainly to seek employment. Universities located in this area are disadvantaged as they have a lower capacity to attract students. Therefore, they play a pivotal social role since they allow students living in an unprivileged area to get a university education at a lower cost with a comparable level of quality. These universities set their fees at a lower average level than universities located in the attractive area. This central issue reduces revenue level and, consequently, affects universities' performance and therefore their ability to receive more POs.

The indicators shown in Table 3 provide an overview of the economic and social gaps that characterize different regions of Italy.

\section{Methodology}

The IHES is facing a crucial phase due to the pattern of reforms that deal with changes in governance mechanisms and financial allocation systems, as described in the previous section. During the last decades, in keeping with HE systems of other European countries, it has been complying with this evolution and, at the same time, has been dealing with funding cuts. In particular, between 2003 and 2016, an overall reduction in academic staff has been observed (Ezza et al., 2019).

With the aim of studying the allocation of POs, a sample consisting of 58 out of the 67 public universities was used. The nine excluded institutions were six 'special HE institutions', the two universities for foreigners in Perugia and Siena and the University of Trento, since it does not receive any budget for recruitment from the central government as a result of specific legislation. The sample was divided into subgroups on the basis of two dimensions. The first classification relied on the first level of Nomenclature of Territorial Units for Statistics (NUTS 1) for the Italian region, which divides Italy into five sub-regions: Northwest Italy; Northeast

Table 3 Some economic indicators per Italian main geographical areas (year: 2018)

\begin{tabular}{llllll}
\hline & Italy & North East & North West & Centre & South and Islands \\
\hline Value added per capita & $25,587.8$ & $30,693.9$ & $31,679.5$ & $27,652.6$ & $16,672.6$ \\
Unemployment rate & 10.6 & 7.0 & 6.6 & 9.4 & 18.4 \\
Unemployment rate $<$ 30 years & 24.8 & 13.4 & 15.5 & 23.0 & 39.8 \\
Employment rate & 31.1 & 38.1 & 41.2 & 39.2 & 24.5 \\
Employment rate < 30 years & 20.9 & 17.9 & 25.7 & 23.4 & 19.4 \\
Students leaving education early & 14.5 & 10.6 & 13.3 & 10.7 & 18.8 \\
\hline
\end{tabular}

Source: Italian Statistics Office — ISTAT 
Italy; Central Italy; South Italy; and Insular Italy. In line with the aim of the study - to understand if the environmental context could affect the university's capability to meet the performance goals used in PO allocation - this geographical categorization was adopted to focus on the different territorial areas.

The second methodological step addressed the development of a dataset. For the 58 universities included in the sample, data were collected from the open data provided by the statistical office of the Ministry of Education (MIUR). The panel data span the period from the adoption of the PO measurement by the MIUR to the last year for which data were available (2012-2018).

Considering the allocative mechanisms established by the legislation, it is worth comparing two of the parameters identified by the competitive allocative mechanisms. Turnover POs, which are related to the number of employees leaving universities each year, can be interpreted as a proxy of recruitment needs in order to guarantee the stability of teaching and administrative staff. Similarly, Total POs measure, for each university, the actual amount of resources available to renew staff or offer an adequate career development path to existing employees. Assuming that if all universities performed in the same way, they would tend to receive a number of Total POs close to Turnover POs, the difference between these two parameters highlights the impact (positive or negative) of the formula-based mechanism. To describe this impact, an indicator was developed with reference to the five areas identified by NUTS 1 (2012-2018) as the ratio of Total POs to Turnover POs. The indicator assumes a value higher than 1 when universities received a share of Total POs higher than the Turnover POs, thus highlighting a rewarding effect of the competitive allocation. If the indicator is lower than 1 , universities in this area were 'punished' by the formula-based mechanism.

To analyse the influence exerted on the PO allocated by the geographical area in which the university is located, the OLS panel regression method was adopted. We used a random effects model as our main variable of interest — 'geographical area' identified by NUTS 1 classification - is time-invariant. Furthermore, the method exploited the longitudinal nature of the data to consider the unobservable heterogeneity among universities. An example of this is managerial ability, which clearly affects performance but cannot be directly observed by the researcher and therefore ends up in the error term, thus biasing the results obtained with OLS. ${ }^{3}$

The dependent variable was the Total PO per 1000 students allocated to the 58 universities included in the sample in the period 2012-2018. This variable was calculated using the number of students enrolled in each university to eliminate the potential bias linked to the size difference of Italian universities (see Table 5). Relating to the independent variable 'geographical area', five dummy variables were developed for the five macro areas to analyse the effect exerted by being located in these different parts of the country. South was identified as a reference area because most of the universities in our sample are located in this geographical area. In light of the relation between Total PO measurement and Turnover POs, which is the reference amount of the POs allotted under the formula, the number of Turnover POs was included as a control variable.

A second model was developed, adopting the following control variables to capture the structural diversity of each university that might potentially influence the dependent variable and to avoid the possibility of confounding effects: the diversity of the offerings within each university, the market orientation, a dummy variable to register whether it had a medical

\footnotetext{
${ }^{3}$ Table 5 shows the Breusch and Pagan Lagrangian multiplier test for random effects. In every column, we rejected the OLS in favour of random effects.
} 
school and the variation in the number of students enrolled in a first-year degree course (firstcycle, second-cycle, and single-cycle courses) as a proxy of a university's attractiveness.

Diversification in HE is considered to be among the major factors that have a positive impact on student choice (Van Vught et al., 2010). Indeed, offering more varied curricula could help universities to become more competitive in terms of their ability to appeal to the needs of wider populations of students and, thereby, increase enrolment figures (Rossi, 2009; Teixeira et al., 2013). In line with previous studies (Cattaneo et al., 2019; Huisman et al., 2015; Rossi, 2009), the diversification in offerings of state Italian universities was measured considering the inverse of the Herfindahl index computed for each university:

$$
\left.V \iota=1 /\left(\sum(X\rangle|/ \mathrm{X}|\right)^{2}\right)
$$

where $X\rangle \mid$ is the number of curricula in discipline $\rangle$ offered by each university $(\mid)$ and $\mathrm{X} \mid$ is the total number of curricula offered by university $\mid$. The index, proposed in the context of concentration in industries (Herfindahl, 1950), takes values between 1 and $n(n$ is the overall number of disciplines) and measures how broad is the range of discipline offered by each university and vice versa. A high value of implies that the university is more diversified, while a lower value of implies that the university is more specialized. To simplify the analysis, the index was further normalized by assuming values between 0 and 1

$$
V^{\prime} \iota=(V \iota-1) /(n-1)
$$

where $\mathrm{n}$ stands for the total number of disciplines. A value of ' $\iota$ closer to 1 means that the university diversity is maximal, while a value closer to 0 implies that the diversity is minimal.

Market orientation was measured by the ratio of the total amount of tuition fees to the sum of the total tuition fees and total state-allocated funding in each year.

Having a medical school was included as it could have an impact on the dependent variable in terms of tuition fees and total budget (Cattaneo et al., 2019).

Finally, the variation in the number of students enrolled in the first year of a first-cycle degree, a second-cycle degree or a single-cycle degree was measured for each university as follows:

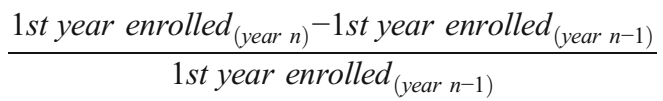

In a third model, additional control variables were included to take into consideration the different social and economic environments in which universities are located. In particular, the logarithm of value added per capita (at province level for each year observed [ISTAT]) and unemployment rate (at province level for each year observed [ISTAT]) were included. Finally, the logarithm of the number of inhabitants (at province level for each year observed [ISTAT]) was incorporated as a proxy for the potential demand. ${ }^{4}$ Table 4 shows the descriptive statistics for the variables used in the random effects regressions.

\footnotetext{
${ }^{4}$ It is worth noticing that several universities offer degree programmes outside the province or the region where the university headquarters are established (10 out of 58 universities offer at least a degree course outside the regional borders, while 49 offer at least a degree outside the province). Nevertheless, these courses attract a limited share of students: only $0.2 \%$ of students are enrolled in degree courses outside the region, while about $8 \%$ of students attend their courses outside the province. Consequently, contextual factors and performance parameters at a province level can be considered adequate proxies of the economic and social environment where a university operates.
} 
Table 4 Descriptive statistics

\begin{tabular}{lllll}
\hline Variable & Mean & Std. Dev. & Min & Max \\
\hline Total PO & 18.053 & 21.054 & 0.350 & 146.060 \\
POs per 1000 students & 0.655 & 0.424 & 0.052 & 2.127 \\
Northeast & 0.172 & 0.378 & 0 & 1 \\
Northwest & 0.190 & 0.392 & 0 & 1 \\
Central & 0.241 & 0.428 & 0 & 1 \\
South & 0.310 & 0.463 & 0 & 1 \\
Island & 0.086 & 0.281 & 0 & 1 \\
Turnover POs & 18.203 & 21.660 & 0.225 & 164.850 \\
Enrolled & $26,415.224$ & $21,441.249$ & 0 & 123,394 \\
Diversification & 0.603 & 0.271 & 0.003 & 0.998 \\
Market Orientation & 0.176 & 0.046 & 0 & .300 \\
Medical School (Yes $=1)$ & 0.707 & 0.455 & -0.366 & 1 \\
Variation in first year enrolled & -0.005 & 0.091 & $13,191.431$ & 47,700 \\
Value added per capita & $24,172.468$ & 7738.194 & 4.228 & 27.808 \\
Unemployment rate & 12.668 & 5.877 & 172,307 & $4,355,725$ \\
Number of inhabitants & $1,243,093.600$ & $1,209,011.700$ & 348.590 & $2,241.130$ \\
Average fee & 1111.478 & 351.170 & & \\
\hline
\end{tabular}

\section{Results}

Figure 1 shows the ratio of Total POs to Turnover POs in the period 2012-2018. The index presents values less than 1 in all the Southern, Central, and Insular universities, while values greater than 1 in the Northern areas show a system split in two. In the period observed, the universities located in the Northern areas gradually 'gained' at the expense of the others.

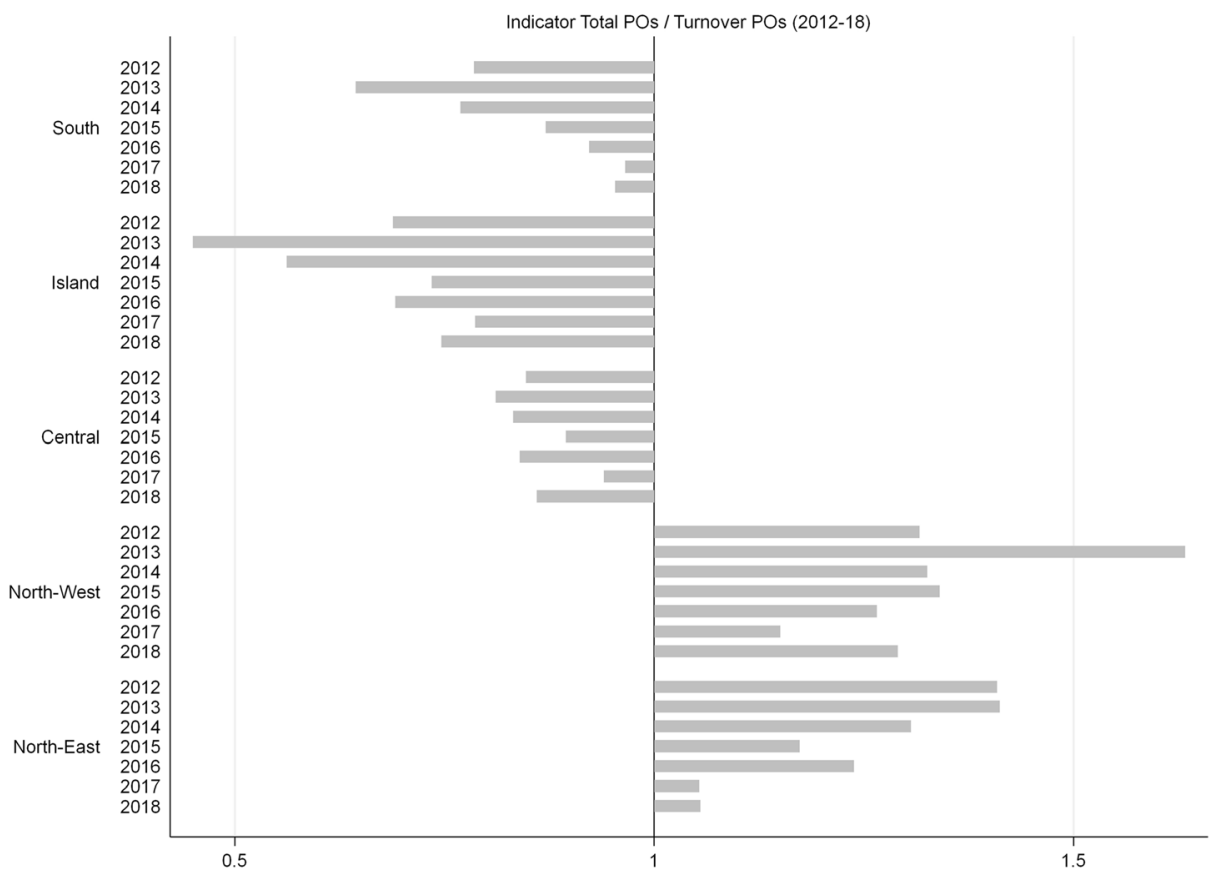

Fig. 1 Indicator 'Total POs/Turnover POs' (2012-2018) 
Table 5 presents the results of the OLS panel regression analysis with random effects at university level in the period 2012-2018. In the columns, the three models are reported. With regard to model 1 , the coefficients for Northeast and Northwest were both positive and statistically significant $(p<0.01)$, revealing that the universities located in these geographical areas received an average Total PO per 1000 of about 0.252 and 0.192 , higher compared to the reference South, while the coefficients for both Centre and Islands are not statistically significant.

The control variable, Turnover POs, was found to be highly statistically significant $(p<$ 0.001) in all three models.

In model 2, among the additional control variables, the diversification of offering was found to be negatively related to POs per 1000 students $(p<0.01)$, suggesting a positive impact in POs for less diversified universities, e.g. polytechnics. Furthermore, the variation in the number of first-year enrolled students showed high statistical significance $(p<0.01)$ and is

Table 5 The influence of geographical area on Total POs per 1000 students

\begin{tabular}{|c|c|c|c|}
\hline & Model 1 & Model 2 & Model 3 \\
\hline Northeast & $\begin{array}{l}0.252 * * * \\
-0.0716\end{array}$ & $\begin{array}{l}0.211^{* * * *} \\
-0.0738\end{array}$ & $\begin{array}{l}-0.208^{*} \\
-0.111\end{array}$ \\
\hline Northwest & $\begin{array}{l}0.192 * * * \\
-0.0694\end{array}$ & $\begin{array}{l}0.112 \\
-0.076\end{array}$ & $\begin{array}{l}-0.221 * \\
-0.113\end{array}$ \\
\hline Central & $\begin{array}{l}0.0481 \\
-0.0649\end{array}$ & $\begin{array}{l}0.0415 \\
-0.0635\end{array}$ & $\begin{array}{l}-0.273 * * * \\
-0.0929\end{array}$ \\
\hline $\begin{array}{l}\text { Island } \\
\text { South }\end{array}$ & $\begin{array}{l}-0.00747 \\
-0.0925 \\
\text { (ref) }\end{array}$ & $\begin{array}{l}0.104 \\
-0.093 \\
\text { (ref) }\end{array}$ & $\begin{array}{l}0.12 \\
-0.096 \\
\text { (ref) }\end{array}$ \\
\hline \multicolumn{4}{|l|}{ Control variables } \\
\hline Turnover POs & $\begin{array}{l}0.0138 * * * \\
-0.000924\end{array}$ & $\begin{array}{l}0.0138 * * * \\
-0.000945\end{array}$ & $\begin{array}{l}0.0155^{* * * *} \\
-0.000982\end{array}$ \\
\hline \multicolumn{4}{|l|}{ University features } \\
\hline Diversification & & $\begin{array}{l}-0.400 * * * \\
-0.118\end{array}$ & $\begin{array}{l}-0.399 * * * \\
-0.122\end{array}$ \\
\hline Market orientation & & $\begin{array}{l}1.124^{*} \\
-0.594\end{array}$ & $\begin{array}{l}1.235^{* *} \\
-0.589\end{array}$ \\
\hline Medical school & & $\begin{array}{l}0.0358 \\
-0.0739\end{array}$ & $\begin{array}{l}-0.0999 \\
-0.0787\end{array}$ \\
\hline Variation in first year enrolled & & $\begin{array}{l}0.766^{* * * *} \\
-0.173\end{array}$ & $\begin{array}{l}0.684 * * * \\
-0.163\end{array}$ \\
\hline \multicolumn{4}{|l|}{ Contextual variables } \\
\hline Value added per capita (Log) & & & $\begin{array}{l}0.467 * * * \\
-0.179\end{array}$ \\
\hline Unemployment rate & & & $\begin{array}{l}-0.0133^{*} \\
-0.00785\end{array}$ \\
\hline Inhabitants (Log) & & & $\begin{array}{l}-0.153^{* * * *} \\
-0.0371\end{array}$ \\
\hline Constant & $\begin{array}{l}0.313 * * * \\
-0.044\end{array}$ & $\begin{array}{l}0.347 * * * \\
-0.112\end{array}$ & $\begin{array}{l}-1.840 \\
-1.607\end{array}$ \\
\hline $\mathrm{N}$ & 405 & 405 & 405 \\
\hline Number of code & 58 & 58 & 58 \\
\hline $\operatorname{chi}^{2}(p$-value $)$ & $\begin{array}{l}254.01 \\
(0.000)\end{array}$ & $\begin{array}{l}323.50 \\
(0.000)\end{array}$ & $\begin{array}{l}419.90 \\
(0.000)\end{array}$ \\
\hline Breusch and Pagan Lagrangian multiplier test chi ${ }^{2}$ ( $p$-value) & $\begin{array}{l}35.17 \\
(0.000)\end{array}$ & $\begin{array}{l}39.74 \\
(0.000)\end{array}$ & $\begin{array}{l}49.68 \\
(0.000)\end{array}$ \\
\hline
\end{tabular}

Random effects model; standard errors in parentheses; stat. sig. * $\mathrm{p}<0.10, * * \mathrm{p}<0.05, * * * \mathrm{p}<0.01$ 
positively related to the dependent variable. This shows the positive impact exerted by higher attractiveness in meeting the performance requirement adopted by the PO allocation mechanism. Market orientation was positively related with Total POs $(p<0.10)$, suggesting that the larger the market orientation, e.g. the weight of students' fees on revenues, the higher its performance in terms of PO. Moreover, having a medical school was not found to be associated with POs. Finally, only being located in the Northeast was found to be positive and statistically significant at $1 \%$.

In model 3, where the contextual variables were included, the positive effect of being located in the Northern areas was captured by the value added per capita, which was statistically significant $(p<0.01)$ and positively related to the dependent variable, and by the unemployment rate, which exerted a negative statistically significant effect on the dependent variable $(p<0.10)$. In addition, the size of the area where the universities are located, measured by the number of inhabitants, was found to be statistically significant at $1 \%$ and negatively related to the dependent variable. After controlling for contextual variables, both the Northern areas and the Central area were found to be statistically significant at $10 \%$ and $1 \%$, respectively, and negatively related to POs per 1000. These latter observations mean that nullifying the contextual setting, universities located in the Northern areas and the Central part of the country received on average fewer Total POs per 1000 students than the universities located in the South. Likewise, in model 2, among the universities' features, Turnover POs, variations in first-year enrolled students (both $p<0.01$ ) and market orientation $(p<0.05)$ were found to be positive and statistically significant, while diversification was still negative and significant at $1 \%$.

\section{Limitations of the study}

As with every empirical analysis, this study presents some limitations. It was carried out within the IHES, observed in the years 2012-2018, and is therefore limited to this context and this temporal period. For this reason, when data become available, the analysis will need to be replicated to include future years' observations.

In addition, it is worth noting that the heterogeneity not observed of the omitted variables has been treated using the random effects model. However, we acknowledge that random effects models are affected by a main limitation in their hypothesis. Moreover, even if our results found a relationship between POs and the independent variables, a causal inference cannot be stated. This requires further analyses that go beyond the aim of this work.

Furthermore, it would be interesting to compare the IHES staff recruitment allocation mechanisms to other HE systems to perform an in-depth investigation of the performance associated with these mechanisms. In this regard, the study of the multidimensional outcomes of universities could be explored in relation to their inputs to better understand their main determinants.

\section{Discussion and conclusion}

The purpose of this study was to investigate some potential effects of the adoption of performance-related mechanisms used to provide universities' staff recruitment budget in the IHES. The analysis aimed to understand if the environmental factors exert an impact on PO allocation mechanisms. 
The findings revealed that universities located in certain geographical areas achieved better performance and, thus, were allocated more resources. The indicator 'Total POs/Turnover POs' showed that in the period observed, universities located in the North received a higher share of resources than those located in the rest of the country. The multivariate analyses confirmed these results. Relative to the South, being located in the North positively influenced the total amount of POs per 1000 students. Specifically, for every 1000 students, universities located in the Northeast and Northwest areas received a respective average Total PO of about 0.252 and 0.192 higher per year than those located in the South. When converting POs into euros, universities located in the Northeast and Northwest received, on average, respective recruitment budgets of $€ 29,000$ and $€ 22,000$ higher per 1000 students per year than those located in the South. As expected, market orientation seemed to play an important role in achieving better performance and affected the PO resources.

Universities that show higher market orientation are capable of obtaining, on average, higher tuition fees from their students. Tuition fees, which represent students' out-of-pocket expenses, can be raised only if the related impact on reducing enrolment is minimal. This possibility is related to university attractiveness: the higher the attractiveness, the higher the potential price that can be set. Heterogeneity in tuition fees was clearly evident in our sample: the mean fees per enrolled student varied greatly, from $€ 728$ paid to the Insular universities to more than $€ 1,200$ paid to the Northern universities. Thus, Northern universities showed higher average values in market orientation than their 'competitors' because of higher attractiveness linked, to some extent, to their greater prestige and the quality standards they have achieved during the last decades.

In this context, it should be noticed that the attractiveness of a university could also depend on contextual factors such as the location (Farhan, 2016), which are only partially manageable by universities. In this sense, higher market orientation is not only favoured by a university's reputation but fostered by the greater opportunities offered to students by a higher quality of services, the alignment between offerings and the labour market, an easy entry into the labour market due to relationships between universities, economic and social fabric, etc. (Cattaneo et al., 2017) which vary greatly throughout the country.

The North has always been the most industrially advanced part of the country, and over time, an unbridgeable gap has grown up with the rest of the country in terms of wealth and labour opportunities that is reflected in individuals' life conditions (ISTAT, 2019). This evidence is in line with the studies by Cattaneo et al. (2017) and Dotti et al. (2013) focusing on universities' ability to attract students in the IHES, which found that students aiming to increase their labour market opportunities and enhance their social status tend to relocate to wealthier areas. Moreover, Cattaneo et al. (2017), analysing the effect of university competition on attractiveness, emphasized that student mobility increased in the last years and that the characteristics that determine university attractiveness are related to the environment context.

In line with these discussions, our findings revealed that among the universities' features, the attractiveness, measured by the variation of first-year enrollment, seemed to positively influence the share of resources obtained by a university, as shown in models 2 and 3. Furthermore, in the same models, diversification of offerings was found to negatively affect the capacity to achieve more POs per 1000 students. Undoubtedly, a higher variety of offerings leads to higher complexity and, in turn, could reduce a university's efficiency. Contrary to our expectations, the presence of a medical school was not found to exert any impact on the dependent variable. 
Among the contextual variables added in model 3, the wealth of a territory - assessed by the value added per capita and the unemployment rate - was found to positively influence the resources allocated to universities located in richer environments. It seems that the higher the economic well-being of a territory, the higher the universities' performance and thus the resources they received. Moreover, the number of inhabitants seems to have a negative influence on POs allocated per 1000 students. Therefore, universities that have received more resources are in the Northwest areas but not in the bigger cities.

Finally, it is worth noting that after controlling for contextual variables (value added per capita, unemployment rate and number of inhabitants), the coefficients of both the Northern areas and the Central area were statistically significant but negatively related to the dependent variable. In fact, not considering the wealth of the areas in which universities are located led to a different effect exerted by the geographical areas. Assuming that the attractiveness of universities has a great impact in achieving more resources and thus POs (because more students lead to higher revenues and fees), when the wealth of territories is captured, mobility from South to North seems irrelevant. In fact, Southern students emigrate seeking better job opportunities and a wealthier environment and seem less affected by universities' features. Therefore, the third model shows that related to the Southern universities, the Northern and Central institutions not only lost their advantage but they obtained fewer POs per 1000 students.

This study contributes to the literature on performance-oriented funding mechanisms in HE systems by investigating the possible effects caused by their adoption. Although several studies have been conducted on the adoption of performance-oriented funding systems, further analyses were required in order to understand the effects produced by these mechanisms in each specific country (Dougherty et al., 2016). The present study was conducted in the IHES and focused on the allocation of public subsidies for staff recruitment. It found that the adoption of performance-based mechanisms rewarded universities located in the North, the wealthier part of the country, strengthening the already considerable differences between the North and the rest of the country (ISTAT, 2019). In other words, results highlighted that the introduction of performance-oriented mechanisms into the IHES has favoured those players that already enjoy a privileged position due to contextual factors. The findings seem to support the conclusions of Hicks (2012): the quest for excellence inherent to performance-based funding systems can result in the reduction of other dimensions, such as equity within the system.

Therefore, this study seems to confirm the risk linked to the adoption of performance-based mechanisms in a heterogeneous context to create a 'winner-takes-all' market (Frank \& Cook, 2010; Jeon \& Kim, 2018; Merton, 1968).

In line with the literature on unintended consequences (Dougherty \& Reddy, 2013), this study found that the effect of the adoption of performance in PO allocation produces unexpected outcomes in terms of the equity of funding allocation (Dowd \& Grant, 2006). The funding mechanisms do not properly consider differences between providers (universities in the IHES) in terms of the contexts in which they operate and, in turn, affect their capacity to achieve better performance. In fact, PO allocation follows a horizontal equity, considering all institutions equal while neglecting the persistent and well-known Italian territorial diversity that should require a vertical equity in terms of the allocation of resources ( $\mathrm{Li}$ et al., 2018).

Further shortcomings seem also to be linked to the main indicators used to assess the performance in PO allocation, which focus only on efficiency as opposed to considering the outcome results (Jongbloed, 2004). This limit refers to the importance of an effective 
performance-oriented system to adopt a broader form of measurements that also include quality and outcome (Geuna \& Martin, 2003).

Therefore, the strategic levers universities can play upon to increase measured performance are not those that improve research outcome or quality. Rather, they should focus on strengthening their efficiency by reducing staff expenses and rental costs and expanding total revenues (tuition fees and governmental funding). As previously noted, it is unsurprising that Northern universities, as well as being more attractive, have benefited from the higher market power that allowed them to both attract more students and increase average tuition fees, thus also increasing the resources available for recruitment. Furthermore, it should be noted that the governmental funding (FFO) is shared through performance-oriented systems. In this sense, the potential effect - the widening of the gap within IHES - may even be amplified. In the long term, the reduction of public resources, be it in terms of POs or FFO, may restrict the capacity of those universities located in disadvantaged areas to guarantee an adequate level of education (Ezza et al., 2017). Consequently, the capacity to fulfil the university's mission, which involves promoting and enhancing knowledge for all citizens equally, could be limited. This could reduce the wellness and community development given the nature of the merit good of HE (Musgrave, 1959, 1995; Pazner, 2007).

Considering the pivotal role played by HE in the development of a country, the main recommendation of this study is to include contextual factors as well as other dimensions of performance in funding allocation to mitigate its unequitable consequences. Furthermore, in addition to performance-based mechanisms adopted to favour best performance, other forms of allocation should be identified which are aimed at supporting those universities located in deprived areas. It should be underlined that in recent years, the Ministry of Education has provided universities with additional POs through extraordinary plans. This incentive should be incorporated into the ordinary funding system and involve pursuing vertical equity in funding (Dowd \& Grant, 2006). Results also suggest that policymakers should identify the correct trade-off between the quest for higher performance within the IHES and the need to guarantee equal and unbiased access to HE services.

Acknowledgments This study contributes to the developmental project of the Department of Business and Economics of the University of Sassari (Dipartimenti di Eccellenza 2018-2022) financed by the Italian Minister of Education.

Funding Open access funding provided by Università degli Studi di Sassari within the CRUI-CARE Agreement. This research was funded by PRIN 2017HBTK5P: From high school to job placement: microdata life course analysis of university student mobility and its impact on the Italian North-Sud divide; P.I. Massimo Attanasio.

Availability of data and material The data that support the findings of this study are available from the corresponding author upon reasonable request.

Code availability Not applicable

\section{Declarations}

Conflicts of interest The authors declare no competing interests. 
Open Access This article is licensed under a Creative Commons Attribution 4.0 International License, which permits use, sharing, adaptation, distribution and reproduction in any medium or format, as long as you give appropriate credit to the original author(s) and the source, provide a link to the Creative Commons licence, and indicate if changes were made. The images or other third party material in this article are included in the article's Creative Commons licence, unless indicated otherwise in a credit line to the material. If material is not included in the article's Creative Commons licence and your intended use is not permitted by statutory regulation or exceeds the permitted use, you will need to obtain permission directly from the copyright holder. To view a copy of this licence, visit http://creativecommons.org/licenses/by/4.0/.

\section{References}

Andresani, G., \& Ferlie, E. (2006). Studying governance within the British public sector and without: Theoretical and methodological issues. Public Management Review, 8(3), 415-431.

Berne, R., \& Stiefel, L. (1984). The measurement of equity in school finance: Conceptual, methodological, and empirical dimensions. Johns Hopkins University Press.

Cattaneo, M., Malighetti, P., Meoli, M., \& Paleari, S. (2017). University spatial competition for students: the Italian case. Regional Studies, 51(5), 750-764.

Cattaneo, M., Horta, H., Malighetti, P., Meoli, M., \& Paleari, S. (2019). The relationship between competition and programmatic diversification. Studies in Higher Education, 44(7), 1222-1240. https://doi.org/10.1080/ 03075079.2018 .1428947$.

Ciriaci, D. (2014). Does university quality influence the interregional mobility of students and graduates? The case of Italy. Regional Studies, 48(10), 1592-1608. https://doi.org/10.1080/00343404.2013.821569.

Dotti, N. F., Fratesi, U., Lenzi, C., \& Percoco, M. (2013). Local labour markets and the interregional mobility of Italian university students. Spatial Economic Analysis, 8(4), 443-468. https://doi.org/10.1080/17421772. 2013.833342.

Dougherty, K. J., \& Reddy, V. (2013). Performance funding for higher education: What are the mechanisms? What Are the Impacts? ASHE Higher Education Report, 39(2), 1-134. https://doi.org/10.1002/aehe.20008.

Dougherty, K. J., Jones, S. M., Lahr, H., Natow, R. S., Pheatt, L., \& Reddy, V. (2016). Looking inside the black box of performance funding for higher education: Policy instruments, organizational obstacles, and intended and unintended impacts. RSF: The Russell Sage Foundation Journal of the Social Sciences, 2(1), 147. https://doi.org/10.7758/rsf.2016.2.1.07.

Dowd, A. C., \& Grant, J. L. (2006). Equity and efficiency of community college appropriations: The role of local financing. The Review of Higher Education, 29(2), 167-194. https://doi.org/10.1353/rhe.2005.0081.

Ezza, A., Pischedda, G., \& Marinò, L. (2017). Performance-based funding in public competition. Lights And Shadows In The Italian Higher Education System. Journal of International Business and Economics, 17(2), 5-22. https://doi.org/10.18374/JIBE-17-2.1.

Ezza, A., Fadda, N., Pischedda, G., \& Marinò, L. (2019). Il “grande gap": gli effetti del performance budgeting sulle politiche di reclutamento delle Università italiane. Management Control, 2, 99-121. https://doi.org/10. 3280/MACO2019-002005.

Faggian, A., \& McCann, P. (2008). Human capital, graduate migration and innovation in British regions. Cambridge Journal of Economics, 33(2), 317-333. https://doi.org/10.1093/cje/ben042.

Farhan, B. Y. (2016). Competitive behaviour in publicly funded academic institutions. Interchange, 47(4), 357373. https://doi.org/10.1007/s10780-016-9283-9.

Frank, R. H., \& Cook, P. J. (2010). The winner-take-all society: Why the few at the top get so much more than the rest of us. Random House.

Geuna, A., \& Martin, B. R. (2003). University research evaluation and funding: An international comparison. Minerva, 41(4), 277-304. https://doi.org/10.1023/B:MINE.0000005155.70870.bd.

Hagood, L. P. (2019). The financial benefits and burdens of performance funding in higher education. Educational Evaluation and Policy Analysis, 41(2), 189-213. https://doi.org/10.3102/0162373719837318.

Herbst, M. (2007). Performance-based budgeting or funding. In M. Herbst (Ed.), Financing Public Universities: The Case of Performance Funding (pp. 65-94). Springer Netherlands. https://doi.org/10.1007/978-1-40209503-0_4.

Herfindahl, O. (1950). Concentration in the US Steel industry, PhD Dissertation, Columbia University.

Hicks, D. (2012). Performance-based university research funding systems. Research Policy, 41(2), $251-261$. https://doi.org/10.1016/j.respol.2011.09.007.

Huisman, J., Lepori, B., Seeber, M., Frølich, N., \& Scordato, L. (2015). Measuring institutional diversity across higher education systems. Research Evaluation, 24(4), 369-379. https://oi.org/10.1093/reseval/rvv021. 
ISTAT. (2019). Rapporto annuale 2019 - La situazione del Paese. Roma.

Jeon, J., \& Kim, S. Y. (2018). Is the gap widening among universities? On research output inequality and its measurement in the Korean higher education system. Quality \& Quantity, 52(2), 589-606. https://doi.org/10. 1007/s11135-017-0652-y.

Johnstone, D. B., Arora, A., \& Experton, W. (1998). The financing and management of higher education: A status report on worldwide reforms. World Bank, Human Development Network, Education.

Jongbloed, B. (2004). Funding higher education: Options, trade-offs and dilemmas. Centre for Higher Education Policy Studies. Accessed 25 April 2017.

Jongbloed, B., Kaiser, F., \& Westerheijden, D. (2017). Improving diversity, quality and efficiency in Dutch higher education using performance agreements. In 39th EAIR Forum 2017: Under pressure? Higher education institutions coping with multiple challenges.

Li, A. Y., Gandara, D., \& Assalone, A. (2018). Equity or disparity: Do performance funding policies disadvantage 2-year minority-serving institutions? Community College Review, 46(3), 288-315. https://doi.org/10. 1177/0091552118778776.

Liefner, I. (2003). Funding, resource allocation, and performance in higher education systems. Higher Education, 46(4), 469-489.

McKeown, M. P. (1996). State funding formulas for public four-year institutions. SHEEO-State Higher Education Executive Officier.

Merton, R. K. (1968). The Matthew effect in science: The reward and communication systems of science are considered. Science, 159(3810), 56-63.

Musgrave, R. A. (1959). The theory of public finance: A study in public economy. McGraw-Hill.

Musgrave, R. A. (1995). Finanza pubblica, equità, democrazia. Il mulino.

Nisar, M. A. (2015). Higher education governance and performance based funding as an ecology of games. Higher Education, 69(2), 289-302. https://doi.org/10.1007/s10734-014-9775-4.

Pazner, E. A. (2007). Merit wants and the theory of taxation. In W. Ver Eechke (Ed.), An anthology regarding merit goods, the unfinished ethical revolution in economic theory. Purdue University Press.

Rossi, F. (2009). Increased competition and diversity in higher education: An empirical analysis of the Italian university system. Higher Education Policy, 22(4), 389-413. https://doi.org/10.1057/hep.2008.33.

Salmi, J., \& Hauptman, A. M. (2006). Innovations in tertiary education financing: A comparative evaluation of allocation mechanisms. Education Working Paper Series, 4, 38324.

Teixeira, P., Rocha, V., Biscaia, R., \& Cardoso, M. F. (2013). Competition and diversification in public and private higher education. Applied Economics, 45(35), 4949-4958.

Umbricht, M. R., Fernandez, F., \& Ortagus, J. C. (2017). An examination of the (un)intended consequences of performance funding in higher education. Educational Policy, 31(5), 643-673. https://doi.org/10.1177/ 0895904815614398 .

van den Brink, M., Fruytier, B., \& Thunnissen, M. (2013). Talent management in academia: performance systems and HRM policies: Performance systems and HRM policies. Human Resource Management Journal, 23(2), 180-195. https://doi.org/10.1111/j.1748-8583.2012.00196.x.

Van Vught, F. A., Kaiser, F., File, J. M., Gaethgens, C., Peter, R., \& Westerheijden, D. F. (2010). The European classification of higher education institutions. CHEPS.

Publisher's note Springer Nature remains neutral with regard to jurisdictional claims in published maps and institutional affiliations. 